\title{
INFEKSI OPORTUNISTIK TINEA CAPITIS PADA PENDERITA PEDICULOSIS CAPITIS
}

\author{
Andi Fatmawati ${ }^{1)}$, Nurhidayat ${ }^{1)}$, Asma Yuliani ${ }^{2)}$. \\ ${ }^{1)}$ Teknologi Laboratorium Medis, Politeknik Kesehatan Muhammadiyah Makassar \\ ${ }^{2)}$ RSIA Paramount \\ Alamat Korespondensi: fatmawati.moe@gmail.com
}

\begin{abstract}
Artikel info:
Received: Desember 2021

Revised: Desember 2021

Accepted: Desember 2021

Publish: Desember 2021
\end{abstract}

\begin{abstract}
Abstrak
Pediculosis capitis merupakan penyakit infeksi pada kulit kepala manusia yang disebabkan oleh infestasi ektoparasit Pediculus humanus capitis yang dapat menular di kepala tanpa disadari karena kontak erat di lingkungan yang sama seperti asrama pesantren. Di kepala penderita pediculosis ditemukan banyak lesi pada kulit, rambut saling melekat, bintik-bintik hitam atau coklat pada pangkal rambut, radang pada kulit kepala serta eksudat nanah yang berasal dari luka gigitan Pediculus humanus capitis yang meradang. Infeksi sekunder berupa tinea capitis dapat menyerang penderita pediculosis. Infeksi ini disebabkan dermatofita genus Microsforum sp dan Trichophyton sp. Penelitian ini bertujuan untuk mengetahui jenis jamur penyebab tinea capitis pada kulit kepala santriwati pesantren di Makassar. Jenis penelitian yang digunakan adalah penelitian deskriptif dengan mengkultur spesimen pada media Sabouraud Dextrose Agar (SDA) dan dilanjutkan dengan identifikasi jamur. Hasil penelitian dari 10 sampel menunjukkan bahwa 1 sampel terinfeksi Microsporum audouinii.
\end{abstract}

Kata Kunci: Pediculosis capitis, santriwati, Tinea capitis

\begin{abstract}
Pediculosis capitis is an infectious disease of the human scalp caused by the ectoparasite infestation of Pediculus humanus capitis which can be transmitted to the head without realizing it due to close contact in the same environment as boarding schools. On the head of a patient with pediculosis, there are many skin lesions, hair sticking together, black or brown spots at the base of the hair, inflammation of the scalp and exudate of pus from the inflamed bite wound of Pediculus humanus capitis. Secondary infection in the form of tinea capitis can attack people with pediculosis. This infection is caused by dermatophytes of the genus Microsforum sp and Trichophyton sp. This study aims to determine the type of fungus that causes tinea capitis on the scalp of female students at the Islamic boarding school in Makassar. The type of research used was descriptive research by culturing specimens on Sabouraud Dextrose Agar (SDA) media and continued with fungal identification. The results of the study of 10 samples showed that 1 sample was infected with Microsporum audouinii
\end{abstract}

Keywords: Pediculosis capitis, female students, Tinea capitis

\section{PENDAHULUAN}

Pediculus humanus capitis atau lebih dikenal di masyarakat umum kutu rambut merupakan parasit yang terdapat pada kulit kepala manusia dan menghabiskan seluruh siklus hidupnya pada manusia. Penyakit ini banyak ditemukan di negara berkembang salah satunya di Indonesia. Pediculus humanus 
capitis dapat menyebabkan penyakit pediculosis capitis (Susanto, et al., 2017).

Pediculus humanus capitis dominan ditemui pada tempat yang berasrama dan berkelompok seperti panti asuhan dan pondok pesantren. Pondok pesantren memiliki resiko prevalensi lebih tinggi terjadi penularan sebab asrama termasuk padat penghuni. Penggunaan tempat tidur, bantal, alas tempat tidur, sisir, aksesoris rambut dan hijab secara bersama dapat beresiko menyebabkan tingginya penularan. Penyakit ini merupakan penyakit menular yang disebabkan oleh perilaku manusia yang kurang menjaga kebersihan pribadi. Penularan Pediculus humanus capitis dapat terjadi ketika adanya kontak rambut secara langsung maupun tidak langsung dengan penderita (Lukman et al, 2018).

Pediculus humanus capitis merupakan infestasi pada kulit kepala manusia yang disebabkan oleh Pediculosis capitis. Penelitian yang dilakukan oleh Nurdiani (2020), melaporkan bahwa prevalensi pediculosis capitis di Pondok Pesantren Mustaqim Jakarta Timur mencapai $64,54 \%$ dari 55 santriwati. Penelitian lainnya dari Jember mencapai 214 74,6\% dari 287 santriwati Pondok Pesantren Miftahul Ulum (Lukman et al, 2018).

Penelitian ini dilakukan di salah satu pondok pesantren di kota Makassar berdasarkan informasi yang diperoleh peneliti bahwa para santriwati yang berada di pondok pesantren tersebut banyak mengalami pediculosis capitis dan belum pernah dilakukan penelitian mengenai hal tersebut.

Pediculus humanus capitis dapat menyebabkan lesi pada kulit kepala dan sering ditemukan dinbagian leher atau belakang kepala. Terjadinya lesi pada kulit kepala manusia ketika terjadi saat Pediculus humanus capitis menghisap darah manusia untuk mendapatkan nutrisi.

Seseorang dikatakan menderita Pediculosis capitis ketika pada kulit kepala ditemukan banyak lesi, rambut saling melekat, bintik-bintik hitam atau coklat pada pangkal rambut, radang pada kulit kepala serta eksudat nanah yang berasal dari luka gigitan yang meradang. Lesi yang sudah kronis akibat gigitan Pediculus humanus capitis dapat mengalami infeksi sekunder berupa infeksi jamur yang akan memperburuk kondisi penderita pediculosis capitis (Alnizar et al, 2017). Salah satu resiko yang dapat ditimbulkan ketika terinfeksi pediculosis capitis kulit kepala penderita berpotensi mengalami infeksi oportunistik berupa Tinea capitis.

Tinea capitis atau yang lebih dikenal dengan dermatofitosis merupakan salah satu penyakit kulit kepala yang disebabkan oleh jamur dermatofita. Dermatofita merupakan golongan jamur yang tumbuh dan melekat pada jaringan keratin yang digunakan sebagai sumber makanan. Terdapat dua jenis spesies jamur dermatofita yang menjadi penyebab Tinea capitis yaitu genus Microsforum $s p$ dan Trichophyton sp. Tinea capitis lebih banyak pada anak dengan rentang usia 314 tahun. Penelitian yang telah dilakukan oleh Siregar 2020, melaporkan bahwa prevalensi di RSUD Dr. Kariadi Semarang mencapai $73,4 \%$ terinfeksi penyakit Tinea capitis, Pada periode 2006-2010 di Rumah Sakit Dr. Wahidin Sudirohusodo Makassar melaporkan mencapai 69,33\% kasus Tinea capitis. Cara penularan Tinea capitis dapat terjadi secara langsung ketika terjadinya kontak kepala seseorang dengan pengidap dan kontak secara tidak langsung melalui sisir, topi, sarung bantal dan alas tempat tidur. Dengan adanya kecocokanantara sel inang dengan lingkungan dapat mempermudah pertumbuhan jamur (Husni et al, 2018).

\section{METODE PENELITIAN}

\section{Alat dan Bahan}

Alat yang digunakan dalam penelitian ini adalah kaca penutup, kaca objek, batang pengaduk, mikroskop, pipet tetes, ose, petridisk, autoclave, inkubator, hot plate, timbangan digital, Erlenmeyer, gelas ukur, beaker glass, sendok tanduk, 
skapel, wadah sampel, bunsen, tabung reaksi, swab steril, dan kapas.

Bahan yang digunakan dalam penelitian ini adalah kerokan kulit kepala santriwati, media Sabouraud Dextrose Agar (SDA), Lactophenol Cotton Blue (LPCB), streptomycin, $\mathrm{NaCl}$ $0,9 \%$ dan aquades.

\section{Prosedur Kerja}

Pengambilan sampel

Disiapkan peralatan yang akan digunakan, kemudian kulit kepala yang akan dikerok dibersihkan dengan menggunakan alkohol 70\%. Setelah itu bagian kulit yang telah dibersihkan dikerok dengan menggunakan skapel. Kemudian hasil kerokan kulit tersebut diambil dengan menggunakan swab steril, kemudian disimpan dalam tabung reaksi yang berisi larutan $\mathrm{NaCl} 0,9 \%$.

\section{Sterilisasi alat}

Sebelum memulai pembuatan media, terlebih dahulu alat-alat yang akan digunakan disterilkan, seperti erlenmeyer, gelas ukur, batang pengaduk, sendok tanduk, petridisk, dengan menggunakan autoclave pada suhu $121^{0} \mathrm{C}$ selama 15 menit.

\section{Pembuatan media SDA}

Media Sabouraud Dextrose Agar ditimbang sebanyak 13gram yang diperoleh dari rumus. Kemudian media yang telah ditimbang dimasukkan kedalam gelas beker, lalu ditambahkan aquades sebanyak $240 \mathrm{ml}$. Setelah itu dipindahkan ke dalam Erlenmeyer, lalu larutan tersebut dihomogenkan kemudian dipanaskan, dan disterilisasi didalam autoclave pada suhu selama 15 menit. Kemudian setelah disterilkan, media dikeluarkan dari autoclave dan dibiarkan sampai suhu $40^{\circ} \mathrm{C}$ lalu ditambahkan $5 \mathrm{~mL}$ amoxicillin trihydrate dengan tujuan untuk mencegah kontaminasi bakteri. Setelah itu media dalam Erlenmeyer tadi dituangkan sebanyak $20 \mathrm{~mL}$ ke dalam petridisk (Kidd et al, 2016). $\begin{array}{cccc}\text { Hasil kerokan } & \text { kulit } & \text { kepala } \\ \text { dilakukan pembiakan } & \text { pada } & \text { media }\end{array}$ Sabouraud Dextrose Agar (SDA) dan diinkubasi pada $\left(25-30^{\circ} \mathrm{C}\right)$ selama 1 minggu. Setelah diinkubasi, kemudian dilakukan pemeriksaan secara makroskopik untuk mengamati pertumbuhan koloni dan secara mikroskopik untuk mengamati morfologi koloni yang tumbuh pada media Sabouraud Dextrose Agar (SDA) (Wahyono, 2016).

\section{Pemeriksaan mikroskopik}

Koloni jamur yang tumbuh pada media Sabouraud Dextrose Agar (SDA) selanjutnya diamati secara mikroskopik untuk memastikan ciri-ciri jamur yang menyebabkan infeksi Tinea capitis.

Untuk melakukan pengamatan secara mikroskopik terlebih dahulu dilakukan persiapan alat dan bahan yang akan digunakan seperti koloni jamur, mikroskop, bunsen, kaca objek, cover glass, ose, larutan Lactophenol Cotton Blue ( $L P C B)$. Kemudian kaca objek yang akan digunakan dibersihkan dengan alkohol agar bebas dari lemak. Setelah itu koloni jamur tersebut diletakkan di atas kaca objek, dan diberi 1 tetes larutan LPCB sampai merata dan ditutup dengan cover glass. Lalu difiksasi dengan api bunsen agar jamur tersebut melekat pada cover glass. Kemudian diperiksa di bawah mikroskop dengan perbesaran lensa objektif 10x untuk mencari lapangan pandang kemudian ke pembesaran 40x, lalu diamati (Ristiari et al, 2018).

\section{Interpretasi hasil}

Spesimen dinyatakan positif jika ditemukan jamur yang sesuai dengan ciri makroskopis dan mikroskopis dermatofita.

\section{HASIL DAN PEMBAHASAN}

Berdasarkan hasil penlitian dari 10 spesimen diperoleh hasil sebagai berikut:

\section{Pembiakan pada SDA}


Tabel 1. Jamur yang ditemukan dari spesimen kerokan kulit kepala

\begin{tabular}{cccr}
\hline Sampel & Jenis Jamur & Nama Jamur & $\begin{array}{c}\text { Hasil } \\
\text { Pemeriksaan }\end{array}$ \\
\hline A & Non-Dermatofita & Mucor circinelloides & Positif \\
B & Non-Dermatofita & $\begin{array}{c}\text { Mucor circinelloides, } \\
\text { Aspergillus fumigatus } \\
\text { Mucor micheli }\end{array}$ & Positif \\
C & Non-Dermatofita & Positif \\
D & Dermatofita & Microsporum audouinii, & Positif \\
& Non-Dermatofita & Aspergillus flavus & \\
E & Non-Dermatofita & Aspergillus fumigatus & Positif \\
F & Non-Dermatofita & Mucor circinelloides & Positif \\
G & Non-Dermatofita & Mucor circinelloides & Positif \\
H & Non-Dermatofita & Aspergillus fumigatus & Positif \\
I & Non-Dermatofita & Aspergillus fumigatus & Positif \\
J & Non-Dermatofita & Mucor micheli & Positif \\
\hline
\end{tabular}

Berdasarkan hasil penelitian yang telah dilakukan secara mikroskopik diperoleh hasil 1 sampel positif dermatofita dan 10 sampel nondermatofita. Jenis jamur yang banyak ditemukan yaitu spesies Mucor $s p$ dan Aspergillus sp. Jenis jamur Aspergillus $s p$ merupakan jamur golongan nondermatofita yang dapat hidup secara saprofit dan hidup bebas.

Pada hasil pemeriksaan kultur atau biakan pada media Sabouraud Dextrose Agar (SDA) menggunakan pewarnaan Lactophenol Cotton Blue (LPCB) ditemukan dua spesies Mucor sp yaitu Mucor circinelloides dan Mucor micheli,dua spesies Aspergillus yaitu Aspergillus flavus dan Aspergillus fumigatus satu spesies Microsporum $s p$ yaitu Microsporum audouinii.

Media Sabouraud Dextrose Agar baik digunakan sebagai media pertumbuhan sebab di dalam media terdapat pepton yang berfungsi untuk menyediakan sumber vitamin dan nitrogen digunakan untuk pertumbuhan organisme di dalam media Sabouraud Dextrose Agar (SDA). Kemudian dextrose yang terdapat di dalam media Sabouraud Dextrose Agar (SDA) berfungsi sebagai sumber energi dan karbon. Sedangkan komponen agar dalam media Sabouraud Dextrose Agar (SDA) berfungsi untuk memadatkan media.

Pengamatan makroskopik pada plate pertama dengan kode $\mathrm{A}$ memiliki bentuk koloni yang bulat kecil. Pada awal pertumbuhan di media Sabouraud Dextrose Agar (SDA) koloni tampak berwarna putih halus kemudian pada hari isolat ke 5 tampak depan dan belakang kuning kecoklatan. Pengamatan secara mikroskopik yang telah dilakukan menunjukkan sporangia berbentuk bulat, columella berbentuk bulat menjadi ellipsoidal, tidak ditemukan klamidospora, dan ditemukan sporangia yang sudah memecah dan keluar dari sporangium. Berdasarkan ciri makroskopik dan mikroskopik yang telah dipaparkan diatas dan telah dibandingkan dengan buku petunjuk Descriptions of Medical Fungi menunjukkan plate A positif Mucor circinelloides.

Pengamatan makroskopik pada plate kedua dengan kode $\mathrm{B}$ memiliki bentuk koloni yang bulat, permukaan koloni memiliki serabut yang halus, Pada awal pertumbuhan di media Sabouraud Dextrose Agar (SDA) koloni tampak berwarna putih halus kemudian pada hari isolat ke 5 tampak kuning kecoklatan. 
Pengamatan secara mikroskopik menunjukkan columella yang bulat, sporangiospora yang tegak dan memiliki cabang yang pendek, tidak ditemukan klamidospora merupakan ciri-ciri jamur Mucor circinelloides. Dan ditemukan pula jamur yang memiliki ciri-ciri berwarna biru, kepala kerucut berbentuk kolom, memiliki columella yang bulat, konidia berbintik pendek, berbentuk kerucut dan berdinding halus yang merupakan ciri-ciri jamur Aspergillus fumigatus.

Pengamatan makroskopik pada plate ketiga dengan kode $\mathrm{C}$ memiliki bentuk koloni yang bulat, bludru, seperti kapas yang halus, berwarna hijau keputihan, warna media tampak depan dan belakang kecoklatan. Pengamatan secara mikroskopik menunjukkan sporangiofor yang tegak,sporangium yang bulat, sporangiospora berwarna kecoklatan, terdapat beberapa klamidospora yang melekat pada sporangium merupakan ciri-ciri jamur Mucor micheli.

Pengamatan makroskopik pada plate keempat dengan kode D memiliki bentuk koloni butiran, datar, coklat kekuningan. Pengamatan secara mikroskopik menunjukkan konidiaspora berwarna coklat yang telah pecah dan berhamburan diluar sporangium, konidiaspora berbentuk bintik pendek, dinding berbentuk halus dan kerucut, kepala konidia yang menyebar merupakan ciri-ciri jamur Aspergillus flavus. Ditemukan pula ciri-ciri jamur yang memiliki klamidospora dinding tebal, bulatan dibagian tengah dengan sporangiospora di depan dan di belakang bulatan merupakan ciri-ciri jamur Microsporum audouinii.

Pengamatan makroskopik pada plate kelima dengan kode $\mathrm{E}$ memiliki bentuk koloni bludru yang halus, pada penggiran koloni berwarna putih dan bagian dalam berwarna abu-abu tua, warna media tampak kuning kecoklatan, berserabut sedikit kasar. Pengamatan secara mikroskopik menunjukkan conidiaspora berwarna coklat yang telah pecah dan berhamburan diluar sporangium, konidiaspora berbentuk bintik pendek, dinding berbentuk halus dan kerucut, sporangiospora yang bercabang dua merupakan ciri-ciri jamur Aspergillus fumigatus.

Pengamatan makroskopik pada plate keenam dengan kode $\mathrm{F}$ memiliki bentuk koloni bulat berserabut kasar, warna media kuning kecoklatan, bludru. Pengamatan secara mikroskopik menunjukkan columella yang bulat, sporangiospora yang tegak dan memiliki cabang yang pendek, tidak ditemukan klamidospora. Dan ditemukan pula jamur yang memiliki ciri-ciri berwarna biru, kepala kerucut berbentuk kolom, memiliki columella yang bulat, konidia berbintik pendek, berbentuk kerucut dan berdinding halus merupakan ciri-ciri jamur Mucor circinelloides.

Pengamatan makroskopik pada plate ketujuh dengan kode $\mathrm{G}$ memiliki bentuk koloni butiran, datar, coklat kekuningan. Pengamatan secara mikroskopik yang telah dilakukan menunjukkan sporangia berbentuk bulat, columella berbentuk bulat menjadi ellipsoidal, tidak ditemukan klamidospora, dan ditemukan sporangia yang sudah memecah dan keluar dari sporangium merupakan ciri-ciri jamur Mucor circinelloides.

Pengamatan makroskopik pada plate $\mathrm{H}$ dan I tidak ditemukan koloni begitupun pada pemeriksaan mikroskopik tidak didapatkan jamur.

Pengamatan makroskopik pada plate kesepuluh dengan kode $\mathrm{J}$ memiliki bentuk koloni berbentuk serabut yang kasar, di sekitar koloni terdapat bintikbintik yang sedikit kasar, warna media tampak kuning keputihan. Pengamatan secara mikroskopik menunjukkan sporangiofor yang tegak,sporangium yang bulat, sporangiospora berwarna kecoklatan, terdapat beberapa klamidospora yang melekat pada sporangium Mucor micheli. 


\begin{abstract}
Menurut Purnama (2016), Lingkungan sangat berperan dalam penyebaran Pediculosis capitis. Menurut Herlina (2013), Pediculosis capitis cepat meluas di lingkungan yang padat dan hygiene yang buruk. Hal ini dikarenakan lingkungan yang padat dapat terjadi intensitas pertemuan yang sering antara santriwati sehingga menimbulkan kebiasaan untuk saling meminjamkan barang pribadi. Salah satu resiko yang dapat ditimbulkan ketika terinfeksi penyakit Pediculosis capitis kulit kepala penderitan berpotensi mengalami infeksi sekunder berupa Tinea capitis. Kondisi asrama santriwati di pondok pesantren cukup padat dengan jumlah santriwati dalam satu ruangan terdapat 20 santriwati dengan lebar ruangan 5 meter dan panjang ruangan 5 meter. Santriwati memiliki kebiasaan menggunakan barang-barang seperti sisir, topi, jilbab, bantal dan penggunaan alas tempat tidur secara bersama.
\end{abstract}

\section{KESIMPULAN}

Berdasarkan hasil penelitian yang telah dilakukan ditemukan jamur dermatofita, yaitu Microsporum audouinii dan jamur bukan dermatofita, yaitu Mucor circinelloides, Mucor micheli, dan Aspergillus flavus.

\section{DAFTAR PUSTAKA}

Alnizar L, Pratiwi A dan Syarifuddin M.A. 2017. Pengetahuan Massyarakat kecamatan Gubeng Kota Surabaya Dalam Mengatasi Infeksi Kutu Kepala (Pedicilosis Capitis). Jurnal Farmasi Komunitas, 4 (2), 43-45.

lukman H, Asri E dan Gustina R. 2018. Identifikasi Deramtofita Pada Sisir Tukang Pangkas di Kelurahan Jati Kota Padang. Jurnal Keshatan Andalas, 7 (3), 331-334.

Kidd, Catriona Halliday, Helen Alexiou, David Ellis. 2016. National
Micology Reference Centre Sa Pathology, Adelaide, South Australia. Jurnal Descriptions of Medical Fungi.

Lukman, Armiyanti Y. dan Agustina D. 2018. Hubungan Faktor-Faktor Resiko Pediculosis capitis terhadap Kejadiannya pada santri di Pondok Pesantren Miftahul Ulum, Jember. Journal of Agromedicine and Medical Sciences, 4 (2), 102-106.

Nurdiani, U. C. 2020. Faktor Faktor Yang Mempengaruhi Pediculosis Humanus Capitis Pada AnakAnak Umur 6-12 Tahun Di Pondok Pesantren Sirojan Mustaqim Dan Penduduk Rw 03 Kelurahan Pondok Ranggon Kecamatan Cipayung Jakarta Timur. Jurnal Ilmiah Analis Kesehatan, 6 (1), 39-41.

Ristiari, N. Julyasih, K. Suryanti, I. 2018. Isolasi Dan Identifikasi Jamur Mikroskopis Rizosfer Tanaman Jeruk Siam. Jurnal Pendididkan Biologi Undiksha, 6 (1), 10-14.

Siregar, N P. F. 2020. Profil Tinea Kapitis Di Poli Kesehatan Kulit Dan Kelamin Rsud Deli Serdang Lubuk Pakam Pada Tahun 2014-2017. Jurnal Ilmiah Simantek Issn. 25500414, 4 (4), 124.

Susanto I, et al. 2017. Buku Ajar Parasitologi Kedokteran edisi keempat, FKUI Jakarta, hal 300.

Wahyono. 2016. Identifikasi Jamur Dermatophyta pada Pakaian Bekas Impor yang Diperjualbelikan Di Kota Makassar. (KTI) tidak diterbitkan. Makassar: Akademis Analis Kesehatan Muhammadiyah Makassar. 